\title{
Environmental Geophysical Study of the Groundwater Mineralization in a Plot of the Cotonou Littoral Zone (South Benin)
}

\author{
Yalo Nicaise, ${ }^{1}$ Descloitres Marc, ${ }^{2}$ Alassane Abdoukarim, ${ }^{1}$ \\ Mama Daouda, ${ }^{1}$ and Boukari Moussa ${ }^{1}$ \\ ${ }^{1}$ Laboratory of Applied Hydrology, Faculty of Sciences and Techniques, University of Abomey-Calavi, 01BP526 Cotonou, Benin \\ ${ }^{2}$ LTHE, IRD, BP 53, 38041 Grenoble Cedex 9, France
}

Correspondence should be addressed to Yalo Nicaise, yalonicaise@yahoo.fr

Received 23 August 2012; Revised 3 October 2012; Accepted 15 October 2012

Academic Editor: Michela Giustiniani

Copyright () 2012 Yalo Nicaise et al. This is an open access article distributed under the Creative Commons Attribution License, which permits unrestricted use, distribution, and reproduction in any medium, provided the original work is properly cited.

Geophysical investigations comprising electrical resistivity and electromagnetic conductivities methods were deployed in a $350 \mathrm{~m}^{2}$ sector, strewn with 11 wells. Within the framework of an environmental study on a small scale in the south of Benin, the water conductivity of these wells was measured to determine in a direct way mineralization of the coastal water table in the littoral zone. This environmental study aimed to prospect by the geophysical methods the space extension of the water table mineralization obtained by direct measurements of water conductivity in the well and the depth of the fresh water/salted water interface in the coastal aquifer. Electromagnetic measurements of conductivities made it possible to chart a gradient of mineralization in the northwest direction. The logs of vertical electric soundings showed a deepening of the fresh water/salted water interface in the southern part and its rupture in the northern part. The electrical resistivities of the interface are sensitive to the degree of its mineralization. It has been observed that the geophysical methods in electrical and electromagnetic prospection are a great contribution to the environmental study of the water table mineralization in the littoral zone for a sustainable management of the water resource.

\section{Introduction}

The zone in the south of the town of Cotonou (economic capital of Benin), lying between the Atlantic Ocean in the south and the most populated city of the country in the north, has vocation to develop and know an economic advancement on the tourist level. This development, thus, will imply an increase in the exploitation of the subsoil water resource a priori of the coastal groundwater aquifer. The knowledge of the extension of the saline water intrusion and depth of the fresh water/salted water interface contributes to the decision making for the safeguard of the environment for the users of the water resource. The saline water intrusion in the aquifers of several coastal zones had like consequences of the acute environmental problems [1]. The deterioration of the fresh water quality in the coastal zone due to the normal sea water infiltration affects the intensive but delicately balanced life of the narrow coastal band [2]. Thus, the cartography of the saline water intrusion will contribute to the maintenance of this delicate balance on the environmental level.

Within the last decade, classic hydrogeological information has been increasingly complemented with subsurface geophysical information that allows obtaining more accurate images of aquifer systems [3-8]. This type of studies has led to the development of the hydrogeophysics discipline [9], in which geophysical methods are used for mapping aquifer subsurface features, estimating properties of the aquifer system, and monitoring distinct dynamic processes, such as seepage in the vadose zone, fluid flow direction, seawater intrusion, and pollutant migration [10]. The surface geophysical methods are noninvasive and constitute profitable solutions of replacement to obtain information on the underground water pollution [2]. The great contrast of 
resistivity between the saturated with salted water formation and that saturated with fresh water was used by a great number of researchers for the study of the saline water intrusion in the coastal sectors [11-14]. Van Dam and Meulankamp [11] estimated the salinity of subsoil water in the western part of The Netherlands by using the method of the resistivities. Their interpretations of the resistivities were near to analytical measurements of the salinity of subsoil waters. The electromagnetic method makes it possible to chart in a noninvasive way the side variations in subsurface of electrical conductivity [15]. The determination of the resistivities by electromagnetic methods can have consequence of the values of resistivities lower than those obtained by measurements of the vertical electric surveys [16]. The principal results obtained during this study will show the contribution of geophysics in the cartography of the saline water invasion in littoral zone aquifer. Knowing that frequent and intensive pumpings in the period of pluviometrical deficit cause a lowering of the tablecloth level and a possible increase towards the grounds of salted bevel [17-19], this study will contribute to an integrated and balanced management of uncontaminated zones with an aim of preserving the environment.

\section{Geological and Hydrogeological Setting}

2.1. Study Site. The littoral environment of Benin is a zone of interface between the tableland at the north and the Atlantic Ocean at the south. The littoral zone in the south of Cotonou is characterized by a subequatorial climate. Pluviometry in this sector is on average $1200 \mathrm{~mm}$ per annum [20]. The variations during the year result in a bimodal regime which make it possible to distinguish a great rainy season from midMarch to mid-July followed by a small rainy season from mid-September to mid-November intercalated, respectively, by small and a great dry season. The average temperature in littoral zone is approximately $27^{\circ} \mathrm{C}$. Within the framework of the study on a small scale, sector of $350 \mathrm{~m}^{2}$ was selected in the littoral zone. The selected sector is between the latitudes north in $701700 \mathrm{~N}$ and $702050 \mathrm{~N}$ UTM coordinates then of longitudes in UTM $424850^{\mathrm{E}}$ and $425200^{\mathrm{E}}$ coordinates. The very little inhabited study site, crossed by the road of fishing, is reserved for the tourist development in the next years (see Figure 1). This development will imply an increase in the demand for groundwater.

2.2. Geology. From the geomorphologic point of view, the littoral is as a whole made up of three sandy bars intersected with muddy levels. These sandy bars consist of accumulations of marine granular sediments, current or inherited of last quaternary transgressions [21]. We distinguish from north to south three generations of sandy bars [22]: the intern bars of yellow sand, the median gray sand bars, and the current and subactual brown gray sand bars. The intern bars of yellow sand are separated of the median gray sand bars by the Outobo lagoon. The median gray sand bars are separated of the subactual brown gray sand bars by the coastal lagoon (see Figure 2). These various sand bars were studied by various authors such as Tastet [23], Lang

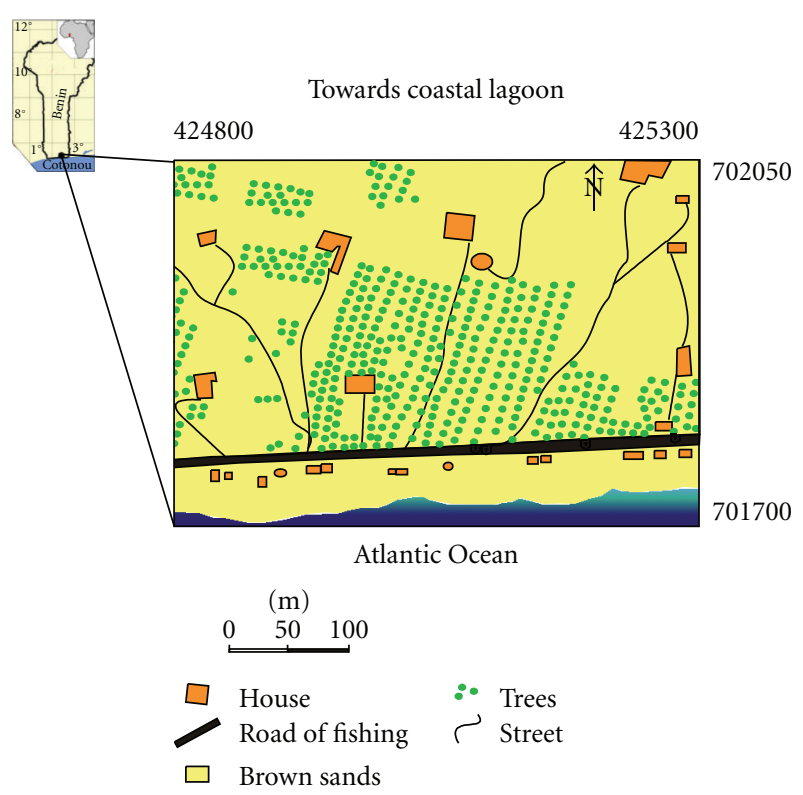

FIgURE 1: Study site map.

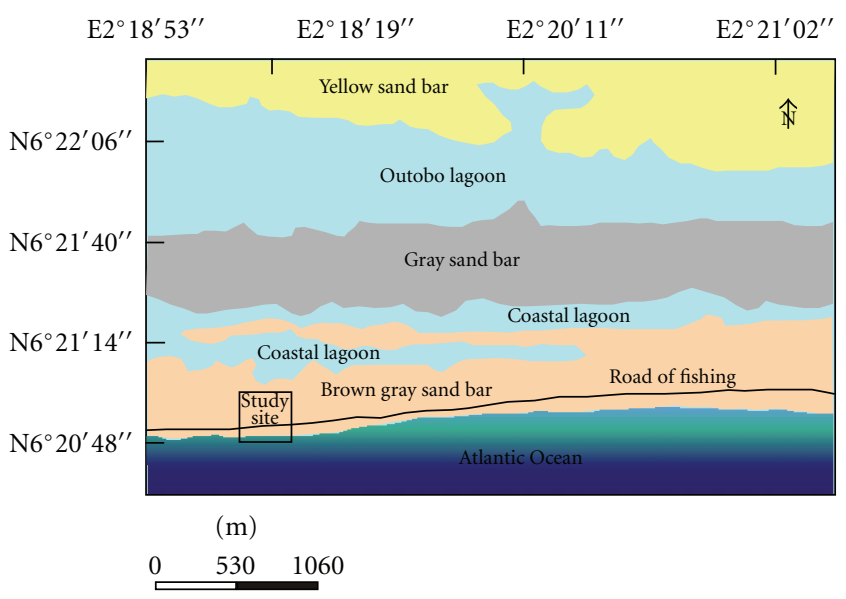

Figure 2: Map of sand bars in littoral plain.

et al. [22, 24], and Kaki et al. [25]. The littoral zone, target of this study, is limited to the current and subactual gray brown sand bar. The deposits of the littoral environment of Benin form a transgressed quaternary sedimentary stacking on the formations of the field of the tablelands [21]. The stratigraphy of the recent Quaternary deposits in the littoral environment of the south of Benin was variously approached by authors such as Lang and Paradis [26], Lang et al. [24], and Marsden [27]. The zone of this study is focused on brown gray sand bars.

2.3. Hydrogeology. In the littoral zone, two aquifers with relatively less potentialities are distinguished: the aquifer of Quaternary and Terminal Continental and that of Paleocene [28]. On the level of the littoral plain, the aquifers are thus superimposed (from bottom to top) the sand aquifer of the Cretaceous; the limestone aquifer of Paleocene; the sand 


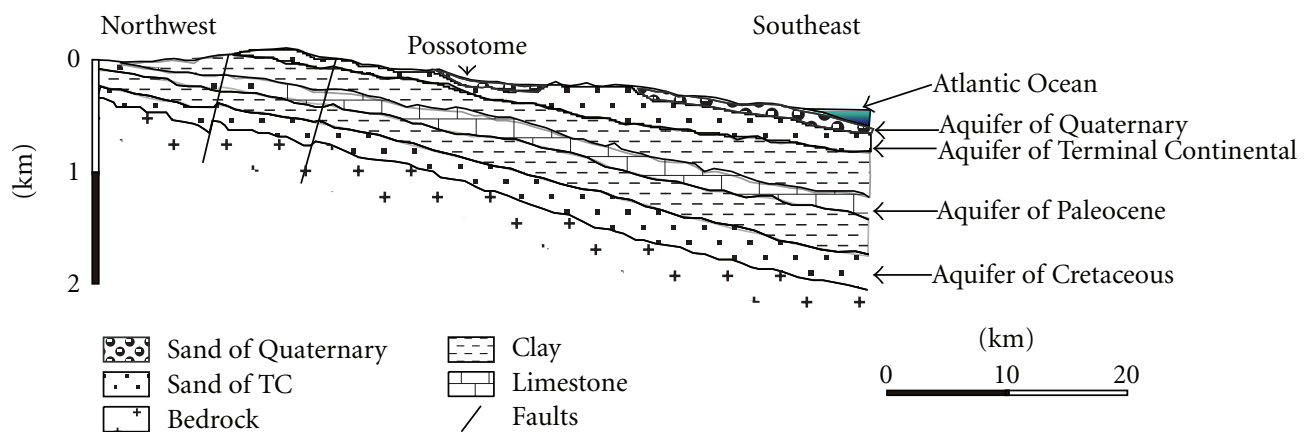

(a)
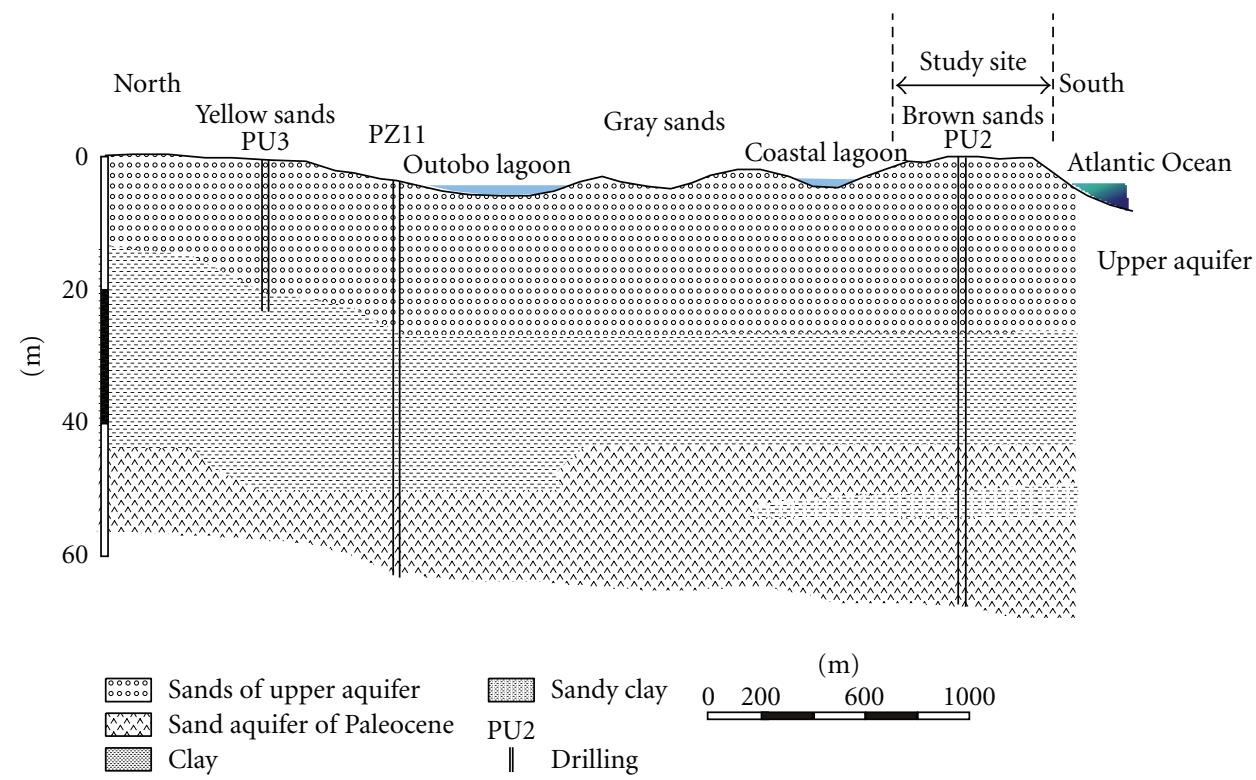

(b)

FIgURE 3: (a) Hydrogeological section of littoral plain. (b) Hydrogeological section of upper aquifer.

aquifer of the Terminal Continental (higher Miocene-Pliocene), and the littoral or alluvial sand aquifer of the Quaternary (see Figure 3(a)). The sandy bars contain an aquifer exploited by wells with flows between 1 and $15 \mathrm{~m}^{3} / \mathrm{h}$. The permeability of sands is raised enough, between $10^{-2}$ and $10^{-4} \mathrm{~m} / \mathrm{s}$. The depth of water level varies from $2,5 \mathrm{~m}$ to $3,5 \mathrm{~m}$ with an annual beat of the order of meter. Fresh water duckweed floats on salted water: water of the Ocean in the south, water of the brackish lagoons in north (Figure 2). In practice, the fresh water can be exploited by wells or not very deep drillings far away from the offshore bar limits.

The PU2 drilling data well in the study zone between the Atlantic Ocean and the coastal lagoon show that the upper sand aquifer thickness does not exceed $30 \mathrm{~m}$ (Figure 3(b)). This upper aquifer is collected by wells and drillings, with depth less than $30 \mathrm{~m}$, in which the water level is between $1 \mathrm{~m}$ and $9 \mathrm{~m}$. The water flow is between 1 and $15 \mathrm{~m}^{3} \mathrm{~h}$. The PU2 drillings only collect deeper aquifers of Paleocene (PU2.2) and Cretaceous (PU2.1).

\section{Material and Methods of Data Acquisition}

Two principal types of geophysical surveys were carried out on the Beninian littoral sector with an aim of charting the salt water intrusion in the surface aquifer. It is the electromagnetic method to measure the side variation of electric conductivity in the sandy aquifer and the method of the vertical electric soundings to estimate in certain points of high conductivity the depth of the fresh water/salted water interface. It was shown that DC resistivity and loop-loop electromagnetic data interpreted together can also help overcome model ambiguities [29].

Another method of direct measurement of the conductivity of water in the wells was used to come in support to the geophysical methods. In our study, the results of geophysical surveys are compared with direct measurement.

3.1. Direct Measurements of Conductivity of Water in the Wells. The direct measurements campaign has been done on midMay 2011 when the great dry season ended and the great 


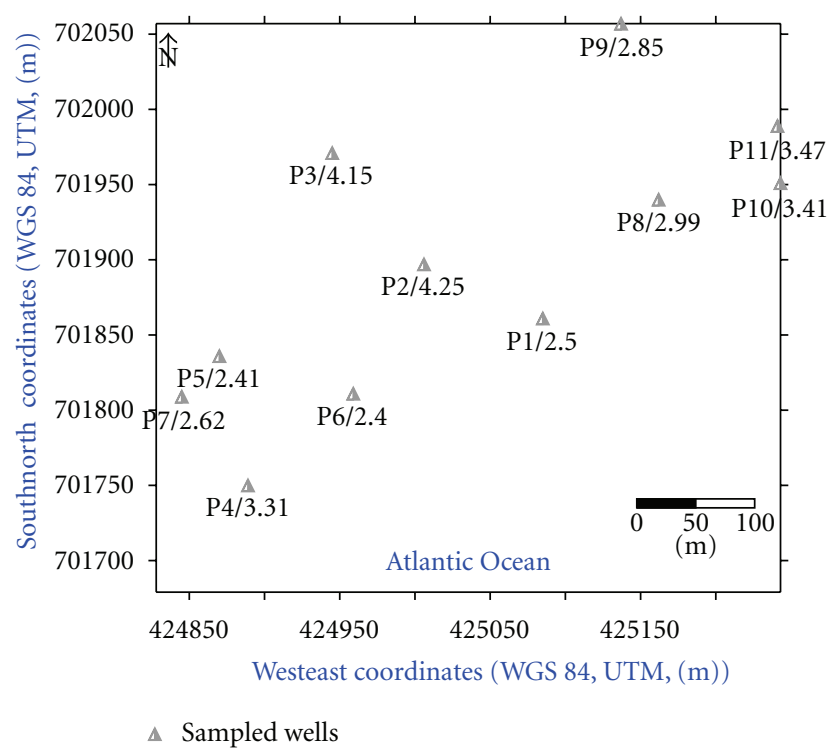

Figure 4: Chart of wells points distribution.

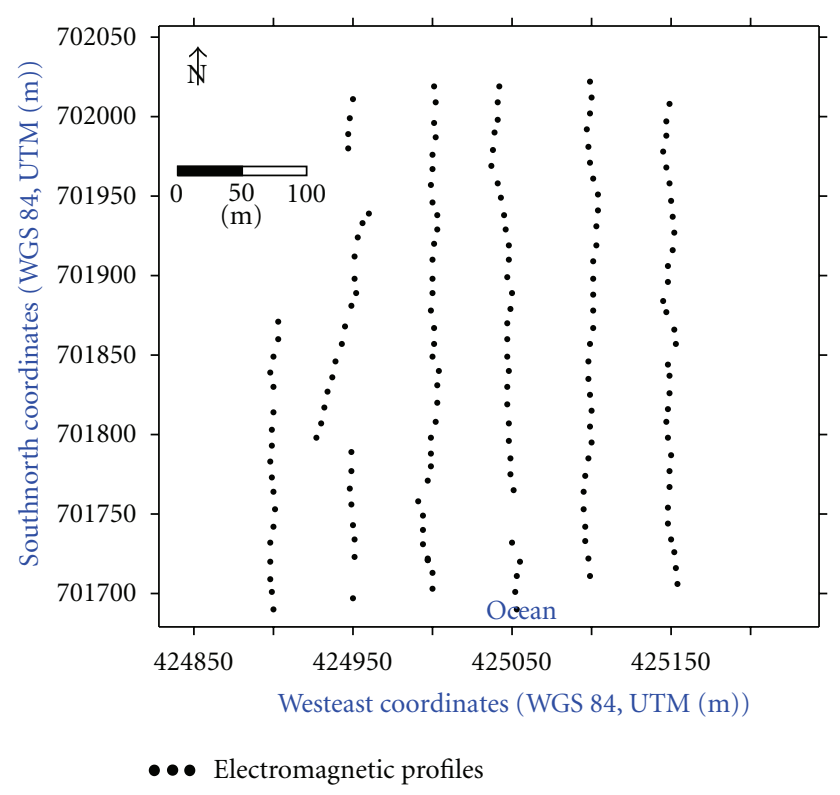

FIgURE 5: Chart of electromagnetic profiles.

limited number of layers depending on the geological background as well as the borehole information in the study area [35], and (c) entering the initial geoelectrical model into the [36] geoelectric modeling package. Each VES is subjected to $1 \mathrm{D}$-forward modeling, in which the iterative procedure of [37] was applied. Iterations were carried out to reach the best fit between the smoothed field curve and the calculated one [38]. Being given that the values of the resistivity connect will be decreasing according to the degree of salinization [39], the objective is to determine the depth of the brackish water, that is, at which depth is fresh water/salted water interface. Five vertical electrical soundings were carried out in the sector of $350 \mathrm{~m}^{2}$. The choice of the site of the soundings was guided by the results of electromagnetic measurements of conductivity. Indeed, the soundings were located in the zones of different electromagnetic conductivities (Figure 8). Vertical electrical sounding VES1 is located in a zone with high conductivity bordering the $60 \mathrm{mSm} / \mathrm{m}$. This zone is near to the ocean. Vertical electrical sounding VES2 is located in a zone with normal conductivity of approximately $46 \mathrm{mSm} / \mathrm{m}$ and a distance of more than $50 \mathrm{~m}$ at north of shore line. Vertical electrical sounding VES3 is located in a zone of low conductivity. This conductivity is around of $36 \mathrm{mSm} / \mathrm{m}$. The VES3 is more than $150 \mathrm{~m}$ at north of shore line. The VES3 is at the west of VES2. Vertical electrical sounding VES4 is located in a zone of very low conductivity at the north of studied area. There the conductivity is around of $28 \mathrm{mSm} / \mathrm{m}$ at more than $250 \mathrm{~m}$ of shore line. As a zone of very low electromagnetic conductivity was detected in the western south of the zone of study, a vertical electrical sounding SEV5 was established there. This sounding was established with $50 \mathrm{~m}$ from the shore and at the west of SEV2 in a zone where electromagnetic conductivity in lower than $20 \mathrm{mS} / \mathrm{m}$. The electromagnetic chart of conductivity was thus used as indicator for the establishment of the vertical electric surveys. These vertical electric surveys were established 


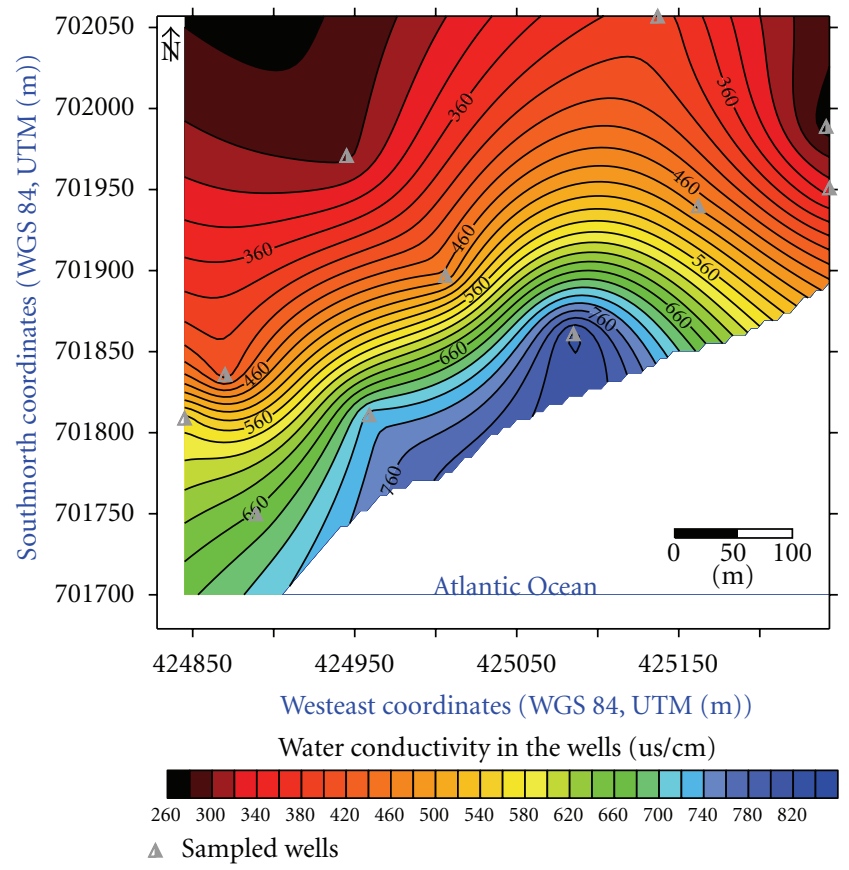

FIgURE 6: Chart of water conductivity.

from south towards north according to the variation of electromagnetic conductivity. Each log of vertical electrical sounding underwent an inversion in the IPI2Win software. This inversion provides a model of geoelectrical distinct grounds. The most conducting grounds are regarded as those containing the brackish or salted water according to their resistivity. In fact, when the resistivity of the conducting ground lies between 0.5 and $5 \Omega \mathrm{m}$, it is supposed to contain salted water (Figure 11). When the conductivity of the conducting ground is slightly higher than $5 \Omega \mathrm{m}$, it is supposed to contain brackish water. For our study, the grounds with resistivities ranging between 5 and $6 \Omega \mathrm{m}$ were regarded as those containing of brackish water. It is in these grounds that the fresh water/salted water interface is.

The southnorth section passing by these vertical electric soundings made it possible to build the fresh water/salted water interface level (Figure 10).

\section{Results and Discussion}

4.1. Results. The values of electric conductivities of water in the wells vary between 271 and $826 \mu \mathrm{Sm} \cdot \mathrm{cm}^{-1}$. These values made it possible to build the chart of conductivities of the mineralization of the water of the wells (Figure 6).

The chart of conductivities of mineralization of water in the wells shows that the water table presents significant variations of mineralization. Electric conductivity is generally high in the south and oscillates between $600 \mu \mathrm{S} \cdot \mathrm{cm}^{-1}$ and $820 \mu \mathrm{S} \cdot \mathrm{cm}^{-1}$, while in north it is generally low and oscillate between $400 \mu \mathrm{S} \cdot \mathrm{cm}^{-1}$ and $260 \mu \mathrm{S} \cdot \mathrm{cm}^{-1}$ (Figure 6). Because of the high number and the good distribution of wells for this reduced sector, the zones presenting similar conductivities could be well delimited in classes. The various classes which allow pronouncing about the degree of mineralization are as follows [40]:

(i) conductivity $<100 \mu \mathrm{S} \cdot \mathrm{cm}^{-1}$ very weak mineralization;

(ii) $100<$ conductivity $<200 \mu \mathrm{S} \cdot \mathrm{cm}^{-1}$ weak mineralization;

(iii) $200<$ conductivity $<333 \mu \mathrm{S} \cdot \mathrm{cm}^{-1}$ medium mineralization;

(iv) $333<$ conductivity $<666 \mu \mathrm{S} \cdot \mathrm{cm}^{-1}$ accentuated mineralization;

(v) $666<$ conductivity $<1000 \mu \mathrm{S} \cdot \mathrm{cm}^{-1}$ significant mineralization;

(vi) conductivity $>1000 \mu \mathrm{S} \cdot \mathrm{cm}^{-1}$ high mineralization.

In all the littoral zone of the studied sector, the mineralization of the water table thus varies from significant value to a medium value passing by an accentuated mineralization value. Water with high mineralization is in southern seashore in contact with the ocean. In the south of the studied sector, any well does not have listed because of the high mineralization of water. The lack of wells in the southeastern part of the studied zone is marked by the break off data interpolation on the chart of mineralization conductivities. The chart of mineralization conductivities presents in consequence a gradient of mineralization with south-east-north-west direction. This gradient of mineralization shows a deepening of the brackish water which marks the fresh water/salted water interface as one moves away from the shore.

The chart of electromagnetic conductivities distribution shows a strong variation as well in the eastwest direction as in the southnorth direction. This rate of variation is estimated 


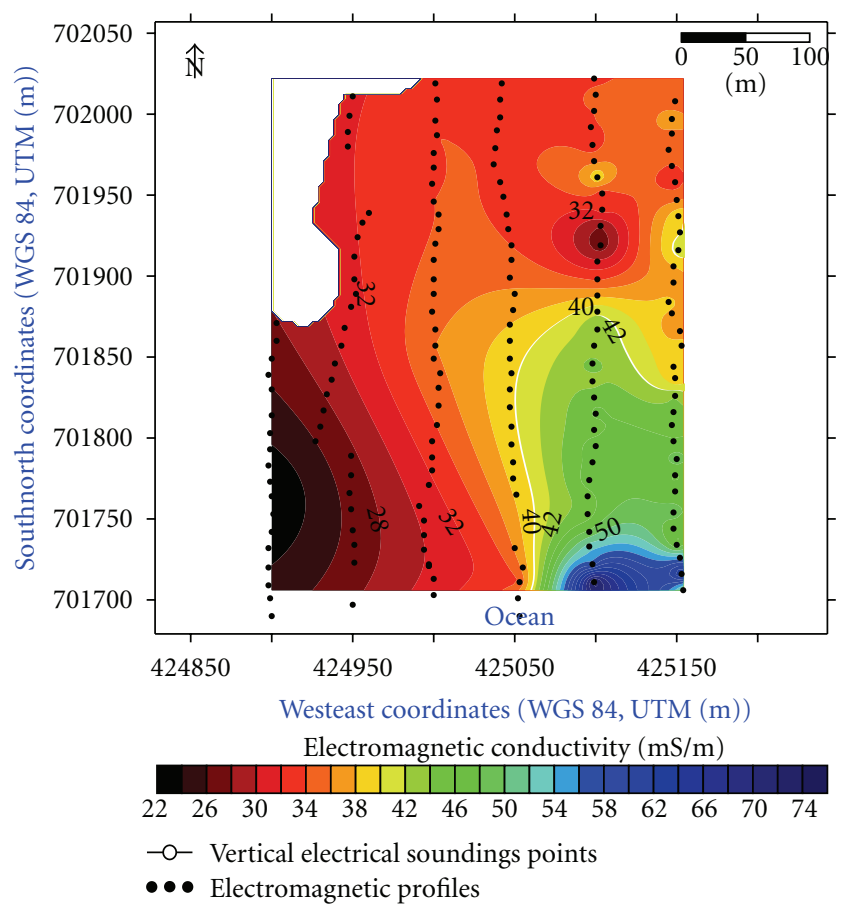

FIgURE 7: Chart of electromagnetic conductivity.

at approximately $(74-30) / 200=0,22$, per meter in E-W direction and $(74-22) / 200=0,26$ per meter in the S-N direction (Figure 7). This rate of variation is representative of the electromagnetic gradient of conductivity. The resulting direction of this gradient orientation would rather be southeast towards the northwest (Figure 7). The chart of electromagnetic conductivities presents a number of low conductivities anomalies. For instance, in the north of the conducting zone, a small resistant anomaly of $30 \mathrm{mS} / \mathrm{m}$ can be due to the influence of the disturbing magnetic effects related to the roof of the houses. These effects will be ignored during interpretation of the chart. In general, the chart of electromagnetic conductivities presents a reduction of conductivity as one moves away from the shore except for the western part studied zone. Nevertheless, it can be retained that the gradient of electromagnetic conductivity remains in conformity with that of the mineralization of water of well.

The vertical electrical soundings were located in the zones of different electromagnetic conductivities (Figure 8).

The log of vertical electric sounding VES1 presents its conducting ground of resistivity $5,04 \Omega \mathrm{m}$ at a depth of $1,02 \mathrm{~m}$ (Figure 9(a)). This low depth of the fresh water/salted water interface is due to the proximity of the shore.

The log of vertical electric sounding VES2 presents its conducting ground of 5,04 $\Omega \mathrm{m}$ resistivity at a depth of $4,75 \mathrm{~m}$ (Figure 9(b)). The fresh water/salted water interface is thus a little deeper at $70 \mathrm{~m}$ from shore.

The log of vertical electric sounding VES3 presents a ground of $5,83 \Omega \mathrm{m}$ resistivity at a depth of $11,6 \mathrm{~m}$ (Figure 9(c)). This significant depth of the fresh water/salted water interface is noticed at $200 \mathrm{~m}$ from shore in the center of the studied zone.

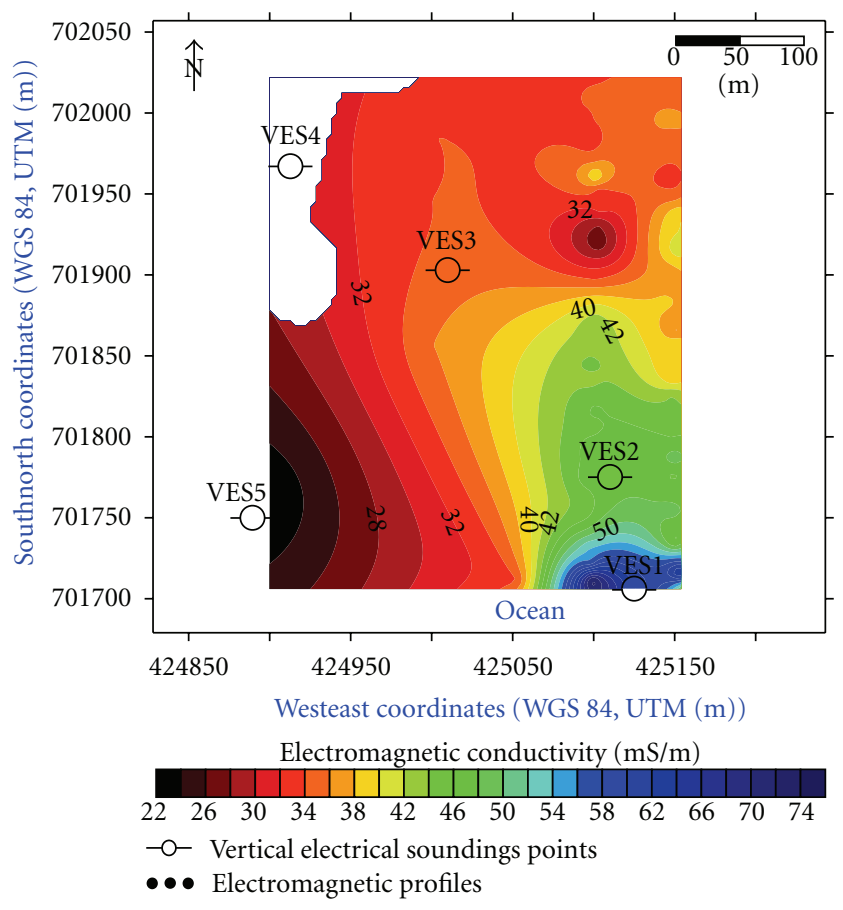

FIGURE 8: VES localization on chart of electromagnetic conductivity.

The log of vertical electric sounding VES4 presents a ground of $5,95 \Omega \mathrm{m}$ resistivity at a depth of $9,79 \mathrm{~m}$ (Figure $9(\mathrm{~d})$ ). This light increase of the fresh water/salted water interface is in the northern part of the zone of study. This zone is furthest away from the shore approximately to $250 \mathrm{~m}$ and marks the end of the deepening of the fresh water/salted water interface.

The northwestern Southeastern vertical section, taking into account the logs of the four vertical electrical soundings, delimits the deepening slope of the fresh water/salted water interface according to the distance from the shore (Figure 10). The deepening slope of this interface remains constant to approximately $5 \%$ up to $200 \mathrm{~m}$ from the shore where a change of incline takes place.

4.2. Discussion. Comparing the electromagnetic conductivity chart with that of mineralization, it is possible to note that the orientation of electromagnetic conductivity gradient is in general in conformity with that of mineralization. Nevertheless, a lack of conformity is noted about a small anomaly and especially in the southeastern part of the studied zone. For $10 \mathrm{~m}$ spacing between the EM34 loops, the depth of investigation is lower than $10 \mathrm{~m}$. Thus, the zones, in which the depth of the fresh water/salted water interface borders exceeds the $10 \mathrm{~m}$ depth, are badly charted by this device. That can explain the anomaly in the center of the studied zone where the interface plunges to more than $10 \mathrm{~m}$ of depth. This device is also sensitive to the surface and very near surface disturbances which could be the cause of the anomaly in the south-east of the studied zone. All things considered, the electromagnetic prospection appears as a tool able to chart the mineralization of the ground water to low 

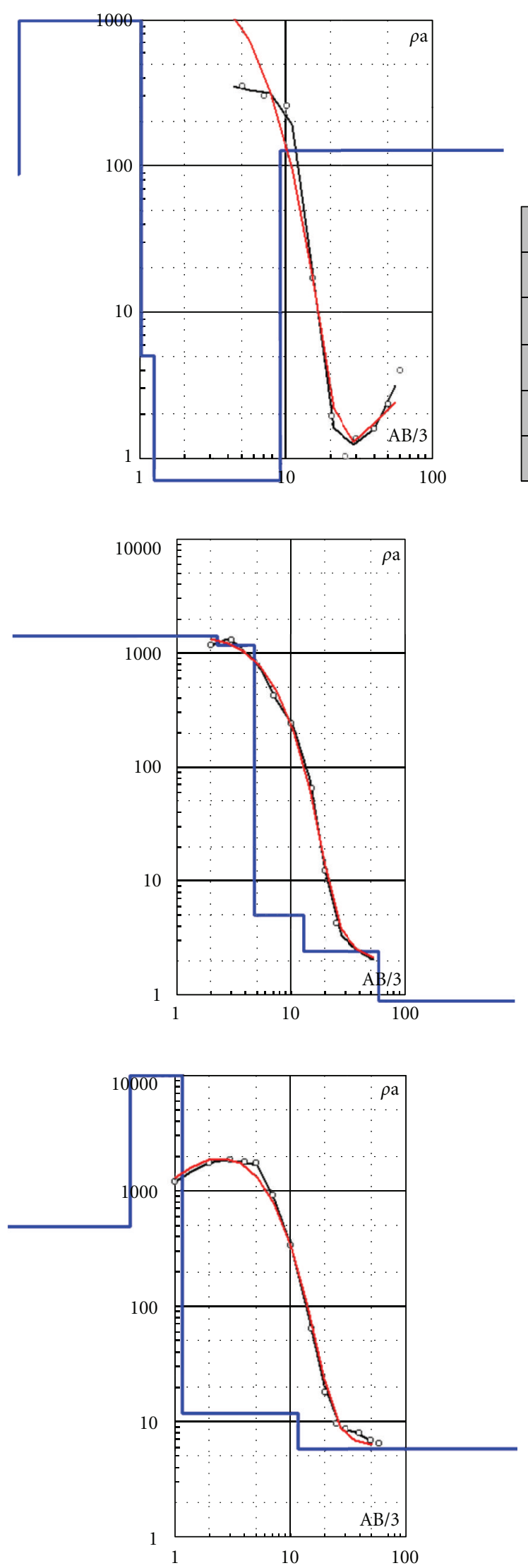

\begin{tabular}{|c|c|c|c|c|}
\hline$N$ & $\rho$ & $h$ & $d$ & Alt \\
\cline { 1 - 4 } 1 & 88.9 & 0.0688 & 0.0688 & -0.0688 \\
\cline { 1 - 1 } 2 & 5892 & 0.947 & 1.02 & -1.016 \\
\cline { 1 - 2 } 3 & 5.04 & 0.228 & 1.24 & -1.244 \\
\cline { 1 - 2 } 4 & 0.248 & 7.72 & 8.96 & -8.964 \\
\cline { 1 - 1 } 5 & 128 & & & \\
\hline
\end{tabular}

(a)

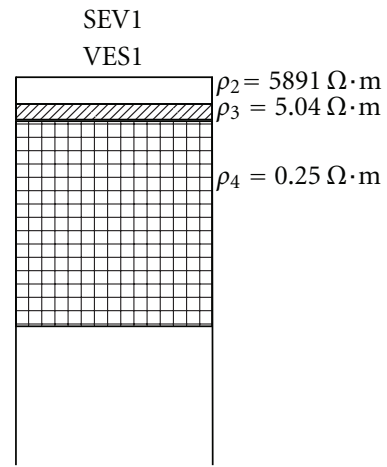

SEV2

\begin{tabular}{|c|c|c|c|c|}
\hline$N$ & $\rho$ & $h$ & $d$ & Alt \\
\cline { 1 - 4 } 1 & 1394 & 2.22 & 2.22 & -2.224 \\
\cline { 1 - 1 } 2 & 1156 & 2.52 & 4.75 & -4.748 \\
\cline { 1 - 1 } 3 & 5.04 & 8.08 & 12.8 & -12.83 \\
\cline { 1 - 1 } 4 & 2.41 & 47.2 & 60 & -60 \\
\cline { 1 - 1 } 5 & \multirow{2}{*}{0.888} & & & \\
\hline
\end{tabular}

(b)

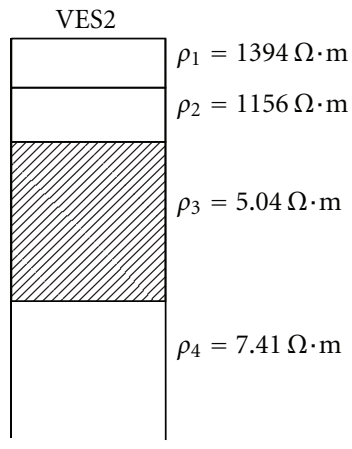

SEV3

VES3

\begin{tabular}{|c|c|c|c|c|}
\hline$N$ & $\rho$ & $h$ & $d$ & Alt \\
\cline { 1 - 2 } 1 & 480 & 0.407 & 0.407 & -0.407 \\
\cline { 1 - 1 } 2 & 10556 & 0.752 & 1.16 & -1.159 \\
\cline { 1 - 1 } 3 & 11.8 & 10.4 & 11.6 & -11.56 \\
\cline { 1 - 2 } 4 & 5.83 & & & \\
\cline { 1 - 1 } & & & & \\
\hline
\end{tabular}

$\rho_{2}=10556 \Omega \cdot \mathrm{m}$ $\rho_{3}=11.8 \Omega \cdot \mathrm{m}$

(c)

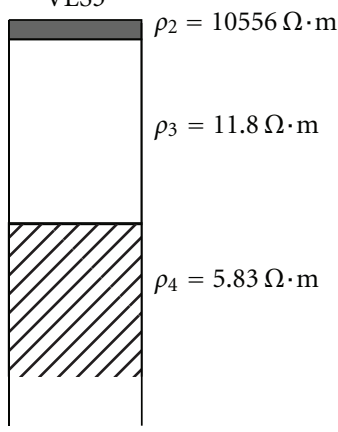

FIgURE 9: Continued. 


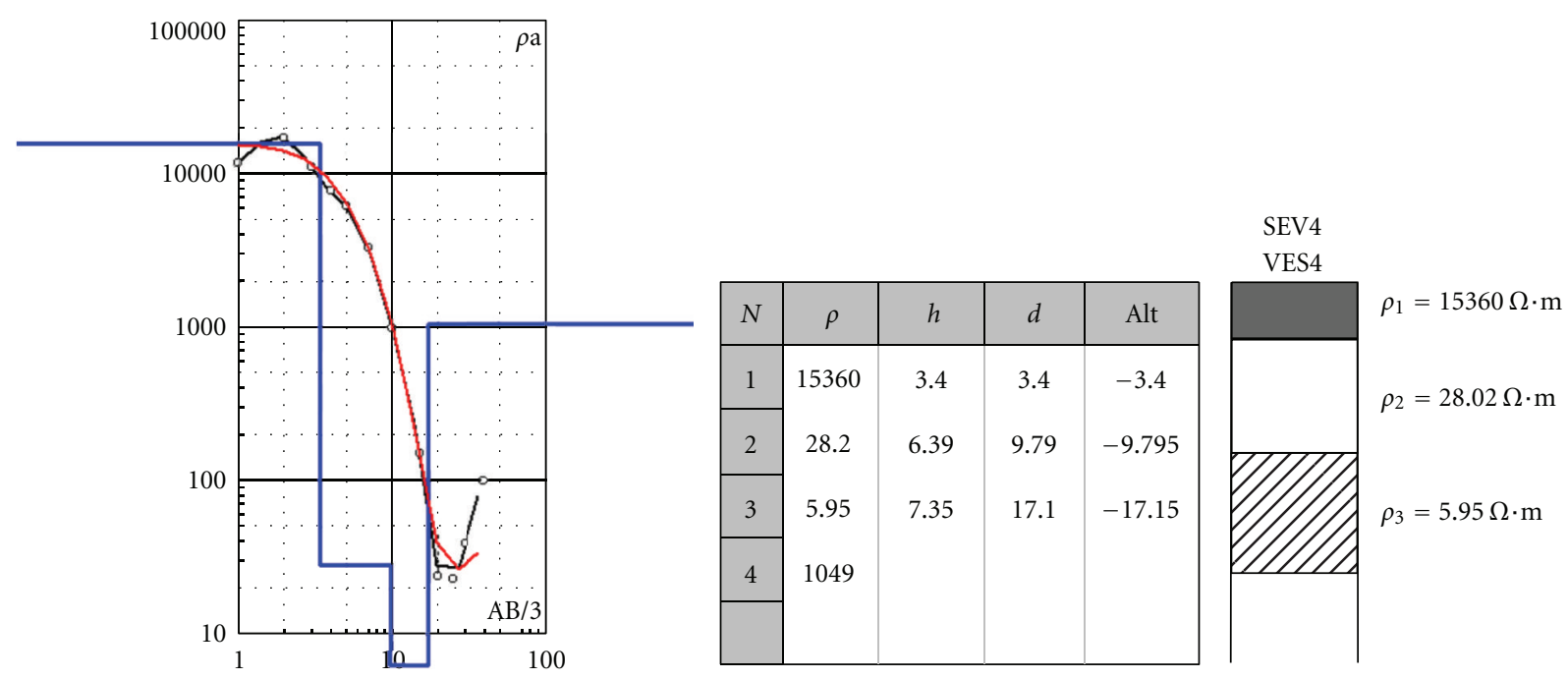

(d)

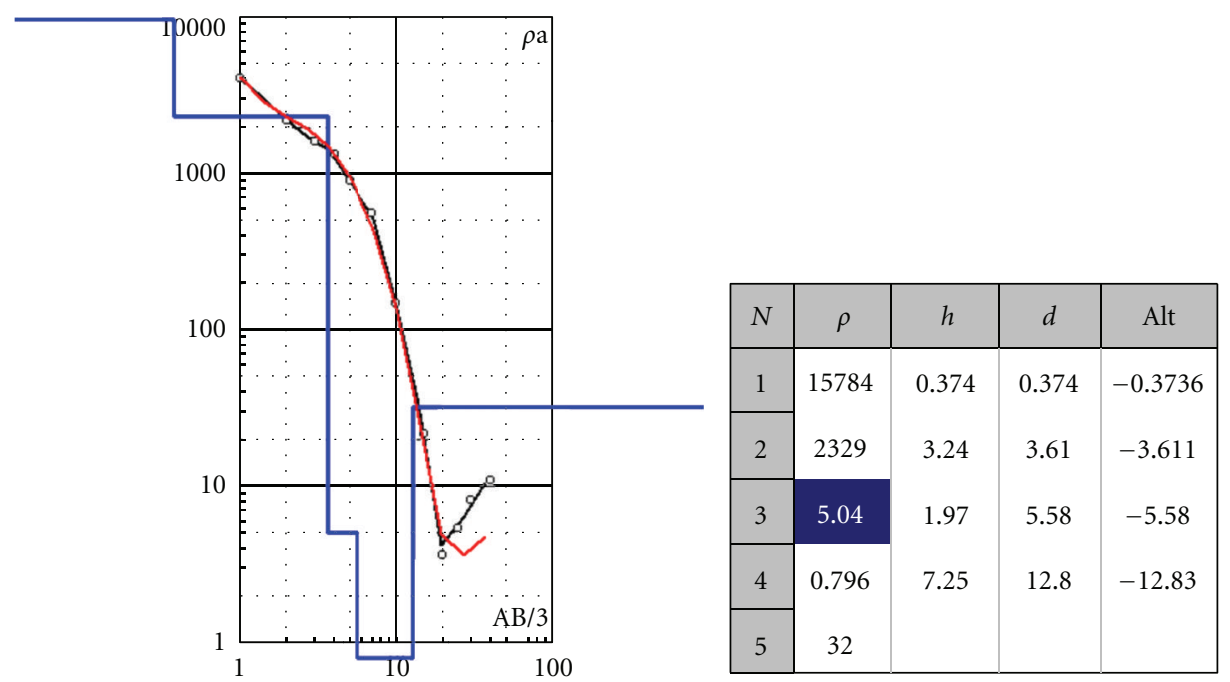

\footnotetext{
- Model layers

Measured log of survey

Calculated log of survey
}

(e)

FIGURE 9: (a) VES1 log and model layers. (b) VES2 log and model layers. (c) VES3 log and model layers. (d) VES4 log and model layers. (e) VES5 log and model layers.

depth in the zones where the electromagnetic disturbances are negligible.

Comparing the deepening slope of the fresh water/salted water interface with the gradient of mineralization, it should be noted that in the south where the interface is close to surface, mineralization is high. Moreover, the weakest variations of the gradient of mineralization in the northern part of the studied zone shows the tendency towards the stability of mineralization when the slope of the interface ceases dipping. The deepening of the interface thus implies a reduction of the mineralization. Moreover, in the southwest where the resistivity of the interface is equal to $5,04 \Omega \mathrm{m}$ for vertical electric sounding VES5, mineralization has a conductivity of
$680 \mu \mathrm{Sm} / \mathrm{cm}$. In the center for the vertical electric sounding VES3 where the resistivity of the interface is equal to $5,83 \Omega \mathrm{m}$, mineralization has a conductivity of $460 \mu \mathrm{Sm} / \mathrm{cm}$. In north for the vertical electric sounding VES4 where the resistivity of the interface is equal to $5,95 \Omega \mathrm{m}$, mineralization has a conductivity of $330 \mu \mathrm{Sm} / \mathrm{cm}$. Thus, on the qualitative level, the low values of resistivities of the interface correspond to a significant mineralization, the medium values of resistivities of the interface correspond to an accentuated mineralization, and the high values of resistivities of the interface correspond to a medium mineralization. The electrical resistivity of the fresh water/salted water interface is thus sensitive to the degree of its mineralization. 


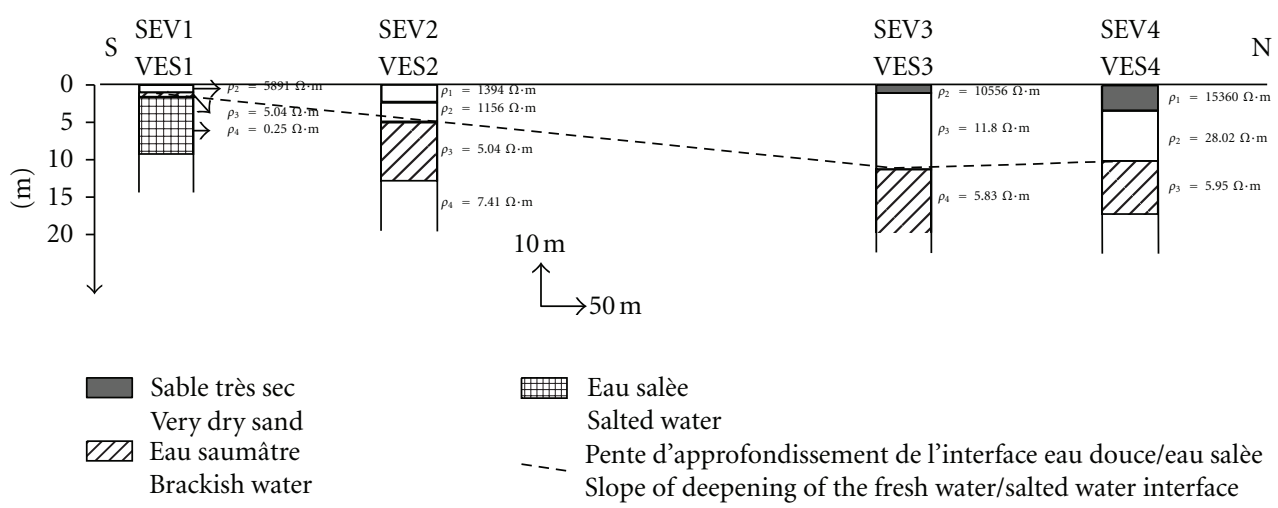

FIGURE 10: Geoelectrical section on the fresh water/salted water interface.

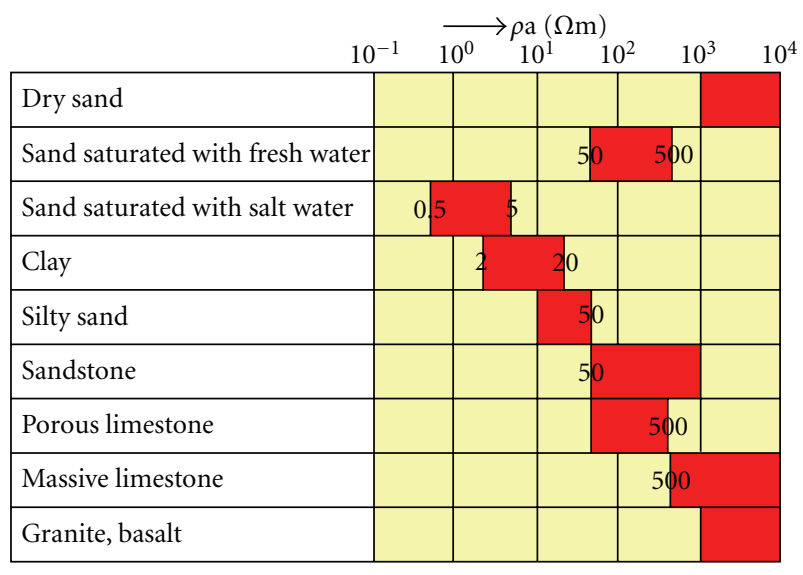

FIGURE 11: Range of rocks resistivity.

Comparing the deepening slope of the fresh water/salted water interface with the gradient of electromagnetic conductivity, it can be noted that the slope and the gradient have a strong variation in the south of studied zone and a soft variation in north. Moreover, in the northern part of the zone where the change of incline is carried out, conductivities remain rather stable. Strong electromagnetic conductivities in the south, where the interface is close to surface, decrease gradually with the deepening of the interface in north. Nevertheless, in the southwestern part where the fresh water/salted water interface is still close to surface, electromagnetic conductivities remain high. This electromagnetic anomaly is partly due to the nature of the surface grounds located at the top of the interface. Indeed, at southwest, the log of vertical electrical sounding VES5 presents at the top of the fresh water/salted water interface, the most resistant ground $(15784 \Omega \mathrm{m}$ ) of the studied zone (Figure $9(\mathrm{e})$ ). Thus, although being able to chart the deepening slope of the fresh water/salted water interface, the electromagnetic gradient can be disturbed by the presence of resistant surface grounds.

\section{Conclusion}

The coupling of the geophysical methods of electromagnetic conductivities and vertical electrical soundings made it possible to chart the mineralization of ground water in the coastal aquifer on the one hand and to detect the depth and the dip of the fresh water/salted water interface in the studied zone on the other hand. The vertical electrical soundings showed that the dip of the fresh water/salted water interface is in the order of $5 \%$ in the southern part of the studied zone, and in the northern part, a change of incline takes place. The variations of the resistivities of the interface are sensitive to the variations of its mineralization. Nevertheless the electromagnetic method is able to define the gradient of mineralization but remains sensitive to the environmental disturbances and to the resistant grounds on the surface.

The geophysical methods in electrical prospection are thus adequate for the cartography of the mineralization of the ground water in coastal zone. On the environmental level, they can be used in the zones where drilling of the wells is difficult, even impossible or useless, in order to delimit the zones where the water resource is sustainability exploitable.

\section{Acknowledgments}

The authors thank, on one hand, the Laboratory of Applied Hydrology (LHA) of the University of Abomey-Calavi in Benin for the facilitation during chemical analysis of the water samples and, on the other hand, the Institute of Research and Development (IRD) of France for the provision of the geophysical material of prospection.

\section{References}

[1] K. Choudhury, D. K. Saha, and P. Chakraborty, "Geophysical study for saline water intrusion in a coastal alluvial terrain," Journal of Applied Geophysics, vol. 46, no. 3, pp. 189-200, 2001.

[2] R. K. Frohlich and D. W. Urish, "The use of geoelectrics and test wells for the assessment of groundwater quality of a coastal industrial site," Journal of Applied Geophysics, vol. 50, no. 3, pp. 261-278, 2002.

[3] W. Schwinn and B. Tezkan, 1D Joint Inversion of Radiomagnetotelluric (RMT) And TrAnsient Electromagnetic (TEM) Data; An Application for Groundwater Prospection in Denmark, Arhus, Denmark, 3rd edition, 1997.

[4] M. J. Unsworth, X. Lu, and M. Don Watts, "CSAMT exploration at Sellafield: characterization of a potential radioactive 
waste disposal site," Geophysics, vol. 65, no. 4, pp. 1070-1079, 2000.

[5] S. Krivochieva and M. Chouteau, "Integrating TDEM and MT methods for characterization and delineation of the Santa Catarina aquifer (Chalco Sub-Basin, Mexico)," Journal of Applied Geophysics, vol. 52, no. 1, pp. 23-43, 2003.

[6] U. Kafri and M. Goldman, "The use of the time domain electromagnetic method to delineate saline groundwater in granular and carbonate aquifers and to evaluate their porosity," Journal of Applied Geophysics, vol. 57, no. 3, pp. 167-178, 2005.

[7] L. B. Pedersen, M. Bastani, and L. Dynesius, "Groundwater exploration using combined controlled-source and radiomagnetotelluric techniques," Geophysics, vol. 70, no. 1, pp. G8G15, 2005.

[8] R. Mota and F. M. dos Santos, "2D sections of porosity and water saturation percent from combined resistivity and seismic surveys for hydrogeologic studies," Leading Edge, vol. 25, no. 6, pp. 735-737, 2006.

[9] Y. Rubin and S. Hubbard, "Hydrogeophysics," Water Science and Technology, vol. 50, p. 521, 2005.

[10] E. Falgàs, J. Ledo, B. Benjumea et al., "Integrating hydrogeological and geophysical methods for the characterization of a deltaic aquifer system," Surveys in Geophysics, vol. 32, pp. 857$873,2011$.

[11] J. C. Van Dam and J. J. Meulankamp, "Some results of the geoelectrical resistivity method in ground water investigations in the Netherlands," Geophysical Prospecting, pp. 92-115, 1967.

[12] A. A. R. Zohdy, "The use of Schlumberger and equatorial soundings on ground water investigation near El Paso Tx," Geophysics, vol. 34, no. 5, pp. 713-728, 1969.

[13] A. Ginsberg and A. Levanton, "Determination of saltwater interface by electrical resistivity sounding," Hydrological Science Bulletin, vol. 21, pp. 561-568, 1976.

[14] R. K. Frohlich, P. J. Barosh, and T. Boving, "Investigating changes of electrical characteristics of the saturated zone affected by hazardous organic waste," Journal of Applied Geophysics, vol. 64, no. 1-2, pp. 25-36, 2008.

[15] R. Rubin and S. S. Hubbard, Eds., Hydrogeophysics, Springer, Amsterdam, The Netherlands, 2005.

[16] R. K. Frohlich, D. W. Urish, J. Fuller, and M. O'Reilly, "Use of geoelectrical methods in groundwater pollution surveys in a coastal environment," Journal of Applied Geophysics, vol. 32, no. 2-3, pp. 139-154, 1994.

[17] J. Handled and V. Meens, "The water soft-water/salted water interface in French Flanders," Bulletin de la Societe Geologique de France, vol. 7, no. 6, pp. 1281-1291, 1984.

[18] J. Mania, S. Imerzoukene, and J. M. Braillon, "Saline pollution of the east Algerian coastal aquifer," Hydrogeologie, vol. 3, pp. 213-226, 1985.

[19] J. C. Grillot and M. Razack, "Space-time Evolution of an alluvial aquifer under the effect of an exceptional multiannual dryness," Journal of Hydrology, vol. 82, pp. 155-173, 1985.

[20] T. Mathias, Climatic variability, the man and the coastal ecosystems dynamics of Benin [Thesis of doctorate], University of Abomey-Calavi, Cotonou, Benin, 2008.

[21] R. A. Laibi, "Evaluation quaternaire et dynamique actuelle des cordons barriers de l'estuaire du Mono-couffo dans le littoral du Bénin (Golfe de Guinée, Afrique de l'Ouest) [Thèse de Doctorat], Université du Littoral Côte Opale, Dunkirk, France, 2001.

[22] L. M. Oyédé, Dynamique sédimentaire actuelle et messages nregistrés dans les séquences quaternaires et néogène du domaine margino-littoral du Bénin (Afrique de l'Ouest) [Thèse de doctorat nouveau régime], Université de Bourgogne et Université nationale du Bénin, 1991.
[23] J. P. Tastet, "Les formations sédimentaires Quaternaires à Actuelles du littoral du Togo et de la République Populaire du Bénin," Supplément du Bulletin AFEQ, no. 50, pp. 155-167, 1977.

[24] J. Lang, G. Paradis, and L. M. et Oyédé, "Le domaine marginolittoral du Bénin (Golfe de Guinée Afrique de l'Ouest) : âge holocène et mise en place des sables jaunes," Journal of Africa Earth Sciences, vol. 7, no. 5-6, pp. 829-833, 1988.

[25] C. Kaki, L. M. Oyédé, and S. et Yessoufou, "Dyamique sédimentaire et environnement côtier du littoral béninois à l'Est de l'embouchure du fleuve Mono," Journal de la Recherche Scientifique de l'Université du Bénin, vol. 5, no. 2, pp. 247-261, 2001.

[26] J. Lang and G. et Paradis, "Le Quaternaire margino-littoral béninois (Afrique de l'Ouest). Synthèse des datations de carbone 14," in Paleoecology of Africa, J. A. et Coetze, E. M. Van Zinderen, and A. A. Baker, Eds., vol. 16, pp. 65-67, Balkema, Rotterdam, The Netherlands, 1984.

[27] D. Marsden, "The automatic fitting of a resistivity sounding by a geometrical progression of depth," Geophysical Prospecting, vol. 21, no. 2, pp. 266-280, 1973.

[28] M. Boukari, "Reactualization of hydrodynamic knowledge relating to the Coastal Sedimentary Basin of the Benin," Support to the Water Stock Management Report (WSMR), Cotonou, Benin, 2002.

[29] M. E. Everett, "Theoretical Developments in electromagnetic induction geophysics with selected applications in the near surface," Surveys in Geophysics, vol. 33, pp. 29-63, 2012.

[30] M. Meybeck, "Chemical composition of the not polluted brooks of France," Sciences Géologiques, vol. 39, pp. 3-77, 1986.

[31] S. M. Lesch, J. D. Rhoades, L. J. Lund, and D. L. Corwin, "Mapping soil salinity using calibrated electromagnetic measurements," Soil Science Society of America Journal, vol. 56, no. 2, pp. 540-548, 1992.

[32] M. E. Cannon, R. C. McKenzie, and G. Lachapelle, "Soil salinity mapping with electromagnetic induction and satellitebased navigation methods," Canadian Journal of Soil Science, vol. 74, no. 3, pp. 335-343, 1994.

[33] D. P. Ghosh, "Inverse filter coefficient for the computation of apparent resistivity standard curves for horizontally stratified earth," Geophys Prospect, vol. 19, pp. 769-775, 1971.

[34] B. Banerjee, B. J. Sengupta, and B. P. Pal, "Apparent resistivity of a multilayered earth with a layer having exponentiality varying conductivity," Geophysical Prospecting, vol. 28, no. 3, pp. 435-452, 1980.

[35] D. Patella, "A numerical computation procedure for the direct interpretation of geoelectrical soundings," Geophysical Prospecting, vol. 23, no. 2, pp. 335-362, 1975.

[36] V. Velpen, Resist: A computer processing package for dc resistivity interpretation for the IBM PC and compatibles [M.S. thesis], ITC, Delft, The Netherlands, 1988.

[37] A. A. R. Zohdy, "A new method for the automatic interpretation of Schlumberger and Wenner sounding curves," Geophysics, vol. 54, no. 2, pp. 245-253, 1989.

[38] M. H. Khalil, "Magnetic, geo-electric, and groundwater and soil quality analysis over a landfill from a lead smelter, Cairo, Egypt," Journal of Applied Geophysics, vol. 86, pp. 156-159, 2012.

[39] M. Boughriba, A. Melloul, Y. Zarhloule, and A. Ouardi, "Spatial extension of salinization in groundwater and conceptual model of the brackish springs in the Triffa plain (northeastern Morocco)," Comptes Rendus_Geoscience, vol. 338, no. 11, pp. 768-774, 2006.

[40] J. Rodier, L'anaLyse de L'Eau, Dunod, 8th edition, 1996. 

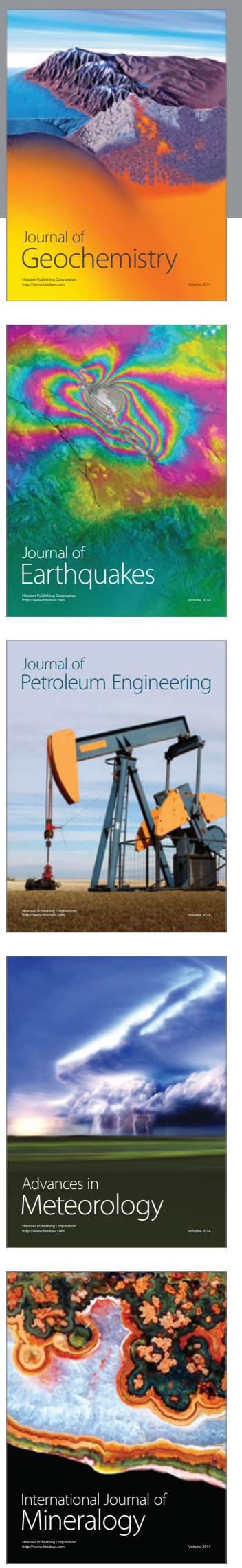
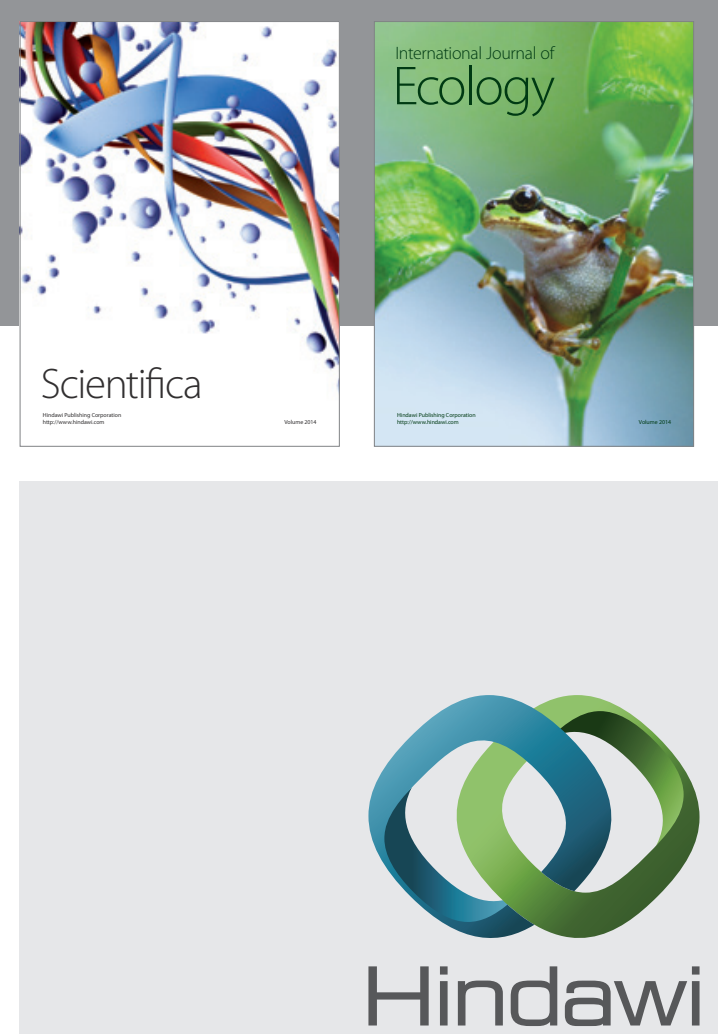

Submit your manuscripts at http://www.hindawi.com
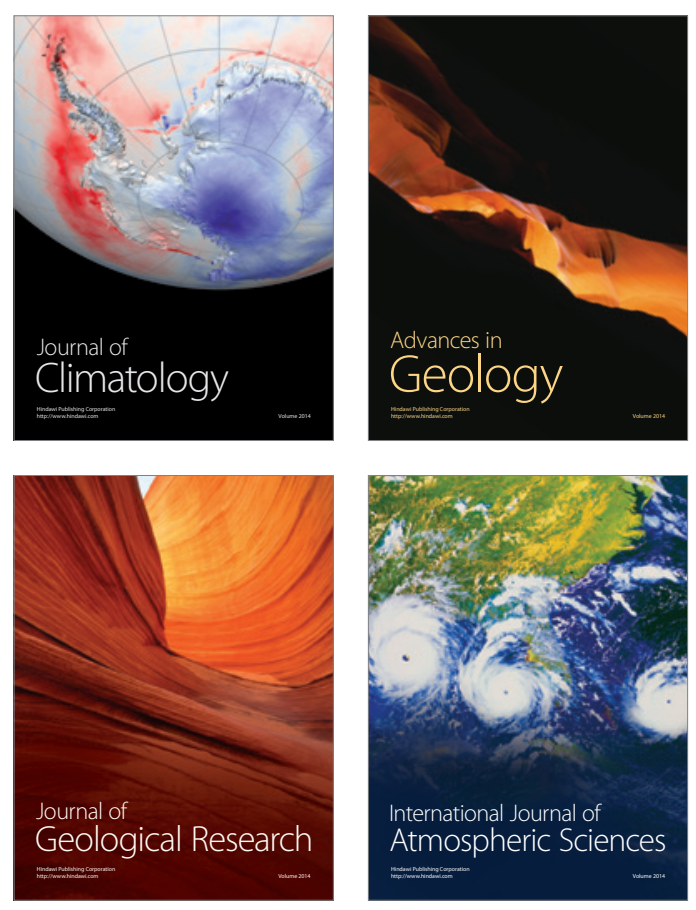
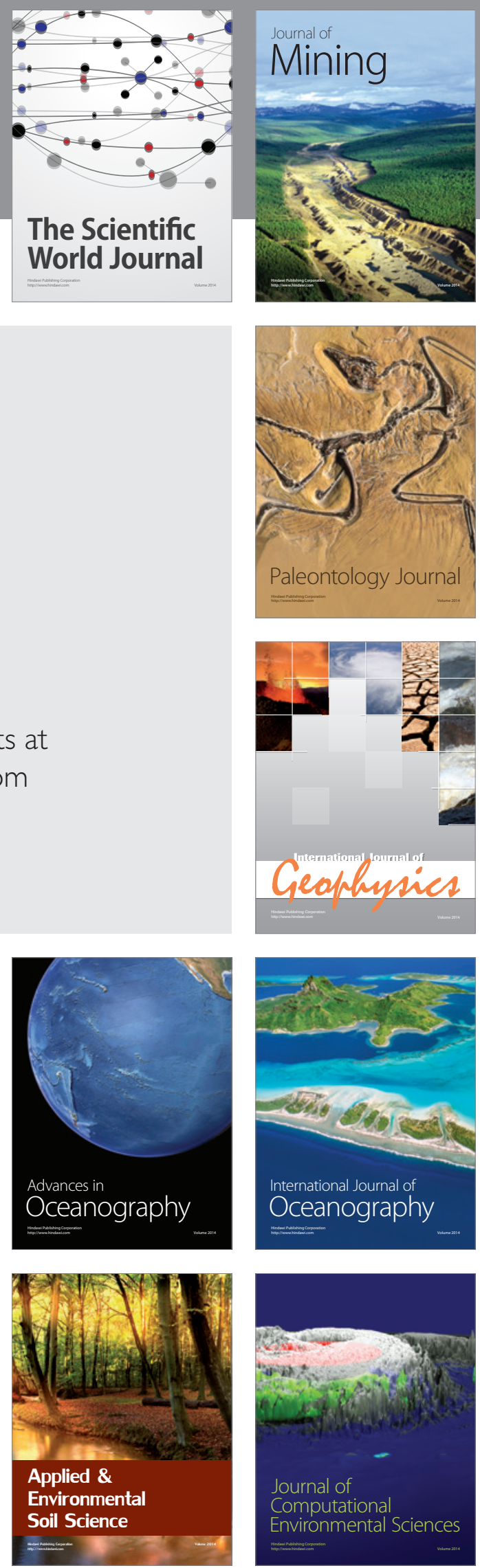